\title{
Silicide Nanopowders as Low-Cost and High-Performance Thermoelectric Materials
}

\author{
RENKUN CHEN ${ }^{1,2}$ \\ 1.-Department of Mechanical and Aerospace Engineering, Materials Science Program, Univer- \\ sity of California, San Diego, La Jolla, CA 92093, USA. 2.-e-mail: rkchen@ucsd.edu
}

Thermoelectric devices directly convert heat into electricity and are very attractive for waste heat recovery and solar energy utilization. If thermoelectric devices can be made sufficiently efficient and inexpensive, then they will become a transformative energy technology that can tap a significant portion $(10-20 \%)$ of the vast amount of heat existing in nature as well as industrial processes. Nanopowders of Earth-abundant, silicide-based materials, such as $\mathrm{Mg}_{2} \mathrm{Si}$ and its alloys, provide a unique opportunity to realize this goal. This article will present an overview of recent advances in the synthesis and thermoelectric properties of silicide-based nanostructured materials.

\section{INTRODUCTION}

Thermal energy plays a very significant role in energy conversion: More than $80 \%$ of the world's electrical power is from heat engines (mostly by burning fossil fuels) and more than $60 \%$ of energy is used in heating and cooling. When the heat source temperature is high and the heat flux is large (such as heat from the $\operatorname{sun}^{1}$ and car exhaust ${ }^{2}$ ), it is extremely desirable to generate electricity from these heat sources as one of the new forms of carbon-free energy. In this respect, thermoelectric (TE) energy conversion has attracted an increasing amount of attention recently ${ }^{3,4}$ due to its potential applications for direct heat to electricity energy conversion for solar energy utilization ${ }^{1}$ and waste heat recovery. ${ }^{5}$

A typical thermoelectric generator (TEG) for direct heat to electricity conversion is shown in Fig. 1a, where $n$ - and $p$-type semiconductor elements are connected in series electrically and in parallel thermally. As the heat is absorbed from the top plate, electrons and holes flow from the hot to the cold sides, thereby creating a continuous electrical current flow through an external load. In essence, the TEG works as a traditional thermodynamic heat engine (such as a Rankine cycle), but it uses electrons and holes as the working fluids rather than fluidic molecules. As such, the TEGs are purely solid-state heat engines and have no moving parts, so they are extremely compact and reliable. These features are attractive for the waste heat recovery scenarios where the extracted electrical power is relatively small compared to a primary power plant.

Despite the attractive potential of TEGs for increasing energy efficiency via waste heat harvesting in various scenarios, the current applications of TEGs are still very limited. This limitation is primarily due to the low efficiency and high cost of the current TE materials. Therefore, it is extremely important to develop efficient and inexpensive thermoelectric materials that would enable the widespread use of TEGs.

The efficiency of the TEGs $\eta$ is determined by the $\mathrm{TE}$ figure of merit referred to as $Z T$, defined as follows ${ }^{6}$ :

$$
Z T=S^{2} \sigma T / \kappa
$$

where $S$ is the Seebeck coefficient, $\sigma$ is electrical conductivity, $T$ is the absolute temperature, and $\kappa$ is the total thermal conductivity that contains both the lattice $\left(\kappa_{\mathrm{L}}\right)$ and electronic $\left(\kappa_{\mathrm{e}}\right)$ components. The maximum efficiency of a TEG in power generation is given by the following relationship:

$$
\eta_{\max }=\left[\frac{T_{\mathrm{h}}-T_{\mathrm{c}}}{T_{\mathrm{h}}}\right]\left[\frac{\sqrt{1+Z \bar{T}}-1}{\sqrt{1+Z \bar{T}}+T_{\mathrm{c}} / T_{\mathrm{h}}}\right]
$$

where $T_{\mathrm{h}}$ and $T_{\mathrm{c}}$ are the temperatures of the hot and the cool sides respectively, and $\bar{T}$ is the average of $T_{\mathrm{h}}$ and $T_{\mathrm{c}}$. The first part of Eq. 2 shows that the maximum efficiency is associated with the temper- 
(a)

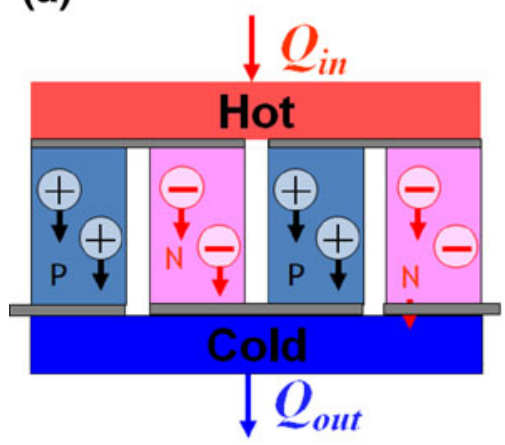

(b)

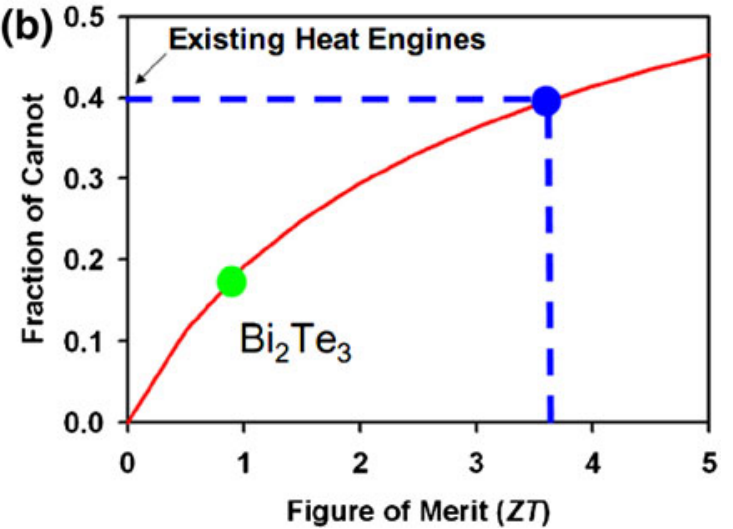

Fig. 1. (a) Schematic of a thermoelectric device that generates electricity from heat current. (b) Maximum efficiency of a thermoelectric device versus the figure of merit $(Z T)$.

ature difference, as dictated by the Carnot efficiency. The relationship between the efficiency $\eta$ and $Z T$ is depicted in Fig. $1 b$.

It is apparent that the figure of merit $Z T$ of $\mathrm{TE}$ materials directly determines the efficiency of $\mathrm{TE}$ devices made from the materials. Enhancing $Z T$ requires concerted engineering efforts to optimize $S$, $\sigma$, and $\kappa$, which contains the electronic $\left(\kappa_{\mathrm{e}}\right)$ and the lattice or phonons $\left(\kappa_{\mathrm{L}}\right)$ components. ${ }^{6}$ In conventional bulk semiconductor materials, the parameters $S, \sigma$, and $\kappa_{\mathrm{e}}$ are often interdependent, which makes it very challenging to independently control these quantities. For example, an increase in $S$ in bulk materials generally results in a simultaneous decrease in $\sigma$; also, an increase in $\sigma$ leads to a comparable increase in electronic contribution to the thermal conductivity $\left(\kappa_{\mathrm{e}}\right){ }^{6}$ As a result, for more than five decades, Bi-Sb-Te-, Pb-Te-, and Si-Gebased alloys have been the primary TE materials with peak $Z T$ around the unity for low, intermediate, and high temperature ranges, respectively, ${ }^{6}$ due to their relatively high power factor $\left(S^{2} \sigma\right)$ and low lattice $\kappa_{\mathrm{L}}$.

Additionally, one also needs to consider other factors when using thermoelectric materials for large-scale applications, such as materials abundance, cost, toxicity, and stability at high temperatures.

\section{ENHANCED $Z T$ BY NANOSTRUCTURING APPROACHES}

During the last decade, the field of thermoelectrics has progressed enormously as evidenced by numerous reports showing enhanced $Z T$ in nanostructured materials ${ }^{7}$ such as superlattices of $\mathrm{Bi}_{2} \mathrm{Te}_{3} / \mathrm{Sb}_{2} \mathrm{Te}_{3}$ (Ref. 8) and PbSeTe/PbTe (Ref. 9), nanowires, 10,11 and in new bulk materials with complex structures ${ }^{12}$ such as silver antimony lead telluride (LAST) ${ }^{13}$ and skutterudites. ${ }^{14}$

The enhanced $Z T$ values in these nanostructured and/or complex-structured materials are attributed to reduced lattice thermal conductivity caused by phonon boundary and defect scattering by nanostructures. This idea is best illustrated by a very recent report by Kanatzidis and co-workers ${ }^{15}$ in which $Z T$ beyond 2 is achieved in $\mathrm{PbTe}$. The high $Z T$ is due to extremely low $\kappa_{\mathrm{L}}$ caused by hierarchical structures with different length scales that scatter the full spectrum of phonons. This approach has been shown to be quite generic provided that the characteristic nanostructure sizes are smaller than phonon mean free path in corresponding bulk materials, which is usually dictated by Umklapp and alloy scattering.

More recently, the trend in thermoelectric research has been shifted to toward developing a scalable route for making thermoelectric nanostructures, and new bulk-nanostructuring approaches have been developed and have achieved very notable success. ${ }^{7}$ As shown in Fig. 2, this new approach is based on the production of bulk thermoelectric composites from nanopowders containing a high density of grain boundaries. The key idea of the nanocomposites is to use the high density of grain boundaries to scatter phonons without significantly adversely affecting the charge transport. The thermoelectric properties of various nanocomposite materials have been reported. ${ }^{16-20}$

Among numerous reports, the most popular methods for producing thermoelectric nanopowders are based on top-down approaches. For example, Poudel et al. ${ }^{17}$ reported the fabrication of nanocomposite $p$-type $\mathrm{Bi}_{0.5} \mathrm{Sb}_{1.5} \mathrm{Te}_{3}$ by ball milling the bulk alloys for extended hours to nanometer dimensions in inert environments and hot-pressing these nanopowders to produce the sintered compacts. They have achieved a high $Z T$ of 1.4 at $100^{\circ} \mathrm{C}$. The same groups also reported a similar ball milling-hot pressing approach for other materials including $\mathrm{Si}-\mathrm{Ge}$ alloy ${ }^{16}$ and $n$-type $\mathrm{Si}^{21}$ among many others. Another recently developed approach is melt-spinning ribbons of the appropriate alloy, hand-grinding them, and compacting them by spark 


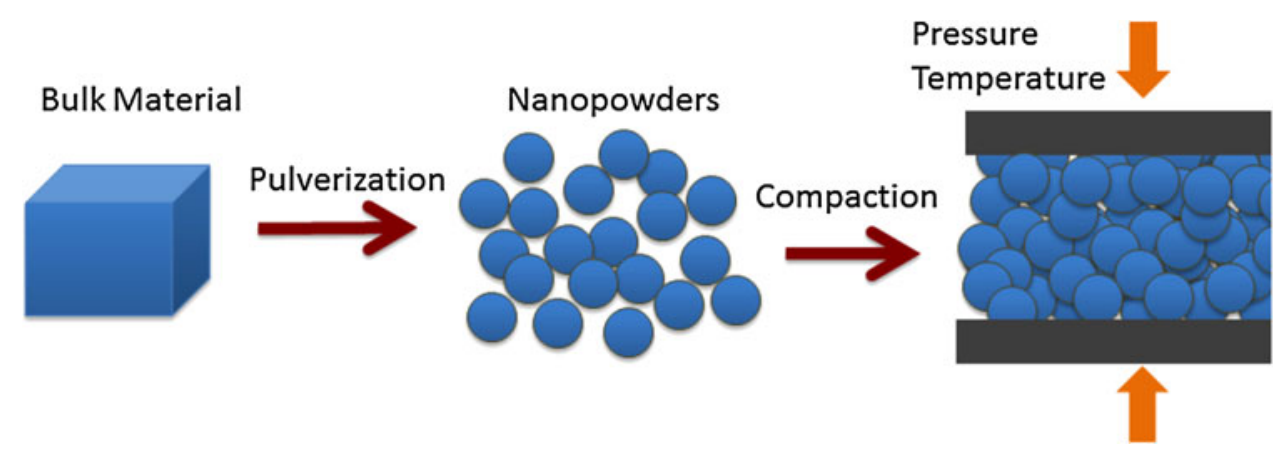

Fig. 2. Schematic of the process for making nanocomposites of thermoelectric materials. The starting bulk material is pulverized into nanopowders by different methods, which are subsequently pressed into compact pellets using processes such as hot pressing and spark-plasma sintering.

plasma sintering (SPS). ${ }^{19}$ A similarly high $Z T$ of $\sim 1.5$ at $360 \mathrm{~K}$ was observed in these $(\mathrm{Bi}, \mathrm{Sb})_{2} \mathrm{Te}_{3}$ nanocomposites.

\section{SILICIDE AS A THERMOELECTRIC MATERIAL}

While nanostructured thermoelectric materials have significantly increased the $Z T$ beyond the unity, the materials ( $\mathrm{Se}, \mathrm{Te}, \mathrm{Sb}, \mathrm{Ge}$, and $\mathrm{Ag}$ ) involved are often not easy-to-scale to high-volume applications such as solar energy utilization and industrial waste heat harvesting, and some materials are toxic (e.g., $\mathrm{Pb}$ ) that would limit their applications in systems such as automobiles. Therefore, there is an increasing amount of effort devoted to alternative thermoelectric materials that are less expensive, more abundant, and nontoxic. This trend has been facilitated by the aforementioned nanostructuring approaches that are used to enhance $Z T$ in materials that are traditionally poor thermoelectric materials, such as $\mathrm{Si}^{10,11,21}$ and PbSe. $^{22}$

A very promising class of Earth-abundant thermoelectric materials is based on silicide, ${ }^{6,23}$ such as $\mathrm{Mg}_{2} \mathrm{Si}$ (Ref. 24), higher manganese silicides $\left(\mathrm{MnSi}_{x}\right.$ ), ${ }^{25,26} \beta-\mathrm{FeSi}_{2}$ (Ref. 27), and $\mathrm{Ru}_{2} \mathrm{Si}_{3}$ (Ref. 28). Silicide alloys are attractive for thermoelectric applications due to their low toxicity, thermal stability, low density, relative abundance, and low cost of production. They are especially attractive for waste heat recovery in the mid-to-high temperature range $(400 \mathrm{~K}$ to $800 \mathrm{~K})$ where they exhibit the peak $Z T$. $^{6,23}$

In this overview, we will focus on $\mathrm{Mg}_{2} \mathrm{Si}$ and its alloy because it has been most widely studied for the thermoelectrics and has shown the highest $Z T$ among the silicide family. $\mathrm{Mg}_{2} \mathrm{Si}$ belongs to the family of magnesium (IV) compounds that crystallizes in the antifluorite structure with $\mathrm{Si}$ in facecentered cubic positions and $\mathrm{Mg}$ in tetrahedral sites $^{29}$ (Fig. 3a). $\mathrm{Mg}_{2} \mathrm{Si}$ is a semiconductor with an indirect bandgap of $\sim 0.78 \mathrm{eV}$, and its room tem- perature mobility is as high as $406 \mathrm{~cm}^{2} / \mathrm{V}$-sec for $n$-type and $56 \mathrm{~cm}^{2} / \mathrm{V}$-sec for $p$-type material. ${ }^{30}$ The exhibited mobilities and bandgap are favorable for thermoelectrics. In 2006, Zaitsev et al. ${ }^{24}$ reported an optimal $Z T$ of 1.1 at around $800 \mathrm{~K}$ for polycrystalline $\mathrm{Mg}_{2} \mathrm{Si}_{0.4} \mathrm{Sn}_{0.6}$ and $\mathrm{Mg}_{2} \mathrm{Si}_{0.6} \mathrm{Sn}_{0.4}$ (Fig. 3b). This high $Z T$ value in $\mathrm{Mg}$-Si-Sn alloy is comparable to the best conventional TE materials such as $\mathrm{Pb}-\mathrm{Te}$, $\mathrm{CoSb}_{3}$, and $\mathrm{Si}-\mathrm{Ge}$ alloys within the temperature range of $400 \mathrm{~K}$ to $800 \mathrm{~K}$. However, unlike these conventional TE materials, the Mg-Si-Sn alloy contains some of the most abundant elements $(\mathrm{Mg}, \mathrm{Si}$, and Sn).

Honda et al. ${ }^{31}$ carried out a very interesting study on $\mathrm{Mg}_{2} \mathrm{Si}$ alloys using reused-Si sludge $(\sim 3.5 \mathrm{~N})$ as a $\mathrm{Si}$ source and recycled $\mathrm{Mg}$-alloys as a $\mathrm{Mg}$ source at a stoichiometric ratio ( $\mathrm{Mg}: \mathrm{Si}=2: 1$ ). The $\mathrm{Mg}_{2} \mathrm{Si}$ alloy was formed by homogeneous melting at $1423 \mathrm{~K}$ while $\mathrm{Bi}$ and $\mathrm{Al}$ were added as $n$-type and $p$-type dopants. The synthesized polycrystalline $\mathrm{Mg}_{2} \mathrm{Si}$ was then pulverized into powders and sintered using a plasma-activated sintering technique. The $Z T$ values were 0.6 at $860 \mathrm{~K}$ for the samples fabricated from reused-Si and recycled Mg-alloys, showing no notable difference compared with specimens fabricated from high-purity $\mathrm{Si}$ and $\mathrm{Mg}$ sources. This study shows that the impurities (such as $\mathrm{Al}$ ) presented in the recycled Mg-alloys can be utilized as dopants for $\mathrm{Mg}_{2} \mathrm{Si}$ without significantly deteriorating its carrier transport properties.

Furthermore, many of the processes creating the nanostructures, such as thin film deposition, are expensive and not scalable. Ball milling ${ }^{17}$ is a process that can make high-volume production of thermoelectric nanopowders, but they often require very long and energy-intensive milling time to make fine powders (more than $10 \mathrm{~h}$ ). In addition, Ball milling is more suitable for brittle materials but not applicable to ductile materials with low Young's modulus. The bottom-up approach for making thermoelectric materials is potentially more scalable but has not been able to produce thermoelectric nanostructures with $Z T>1$. 
(a)

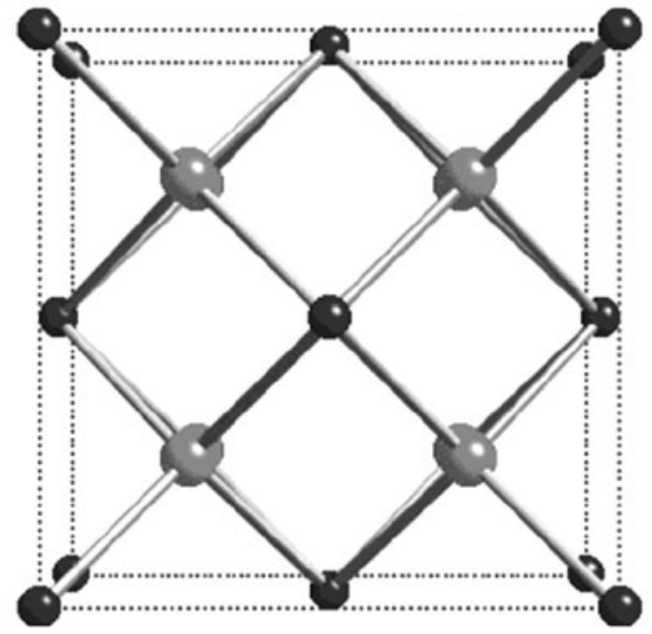

(b)

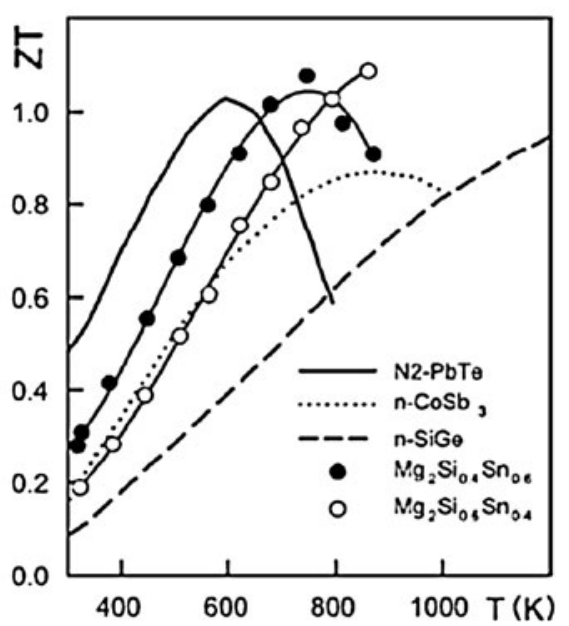

Fig. 3. (a) Unit cell of $\mathrm{Mg}_{2} \mathrm{Si}$. It is a face-centered $(\mathrm{Fm} 3 \mathrm{~m})$ lattice, with a simple cubic lattice of $\mathrm{Mg}$ atoms such that each $\mathrm{Mg}$ (large gray circles) is coordinated by four $\mathrm{Si}$ atoms in a regular tetrahedron, while each $\mathrm{Si}$ (small black circles) is surrounded by a regular cube of eight Mg atoms (Reprinted with permission from Ref. [29], Copyright 2003, American Chemical Society). (b) TE figure of merit $Z T$ of the $\mathrm{Mg}_{2} \mathrm{Si}-\mathrm{Mg}_{2} \mathrm{Sn}$ alloys, in comparison with the best bulk TE materials within the similar temperature range (Reprinted with permission from Ref. [24], Copyright 2006, American Physical Society).

\section{FABRICATION AND THERMOELECTRIC PROPERTIES OF SILICIDE NANOPOWDERS}

In view of the success of various nanostructuring approaches for enhancing $Z T$ in conventional thermoelectric materials, it is then natural to extend the ideas to silicide, in particular $\mathrm{Mg}_{2} \mathrm{Si}$ and its alloys. Here, we summarized some of the popular techniques that have been employed to fabricate nanopowders of $\mathrm{Mg}_{2} \mathrm{Si}$ and its alloys and their thermoelectric properties.

\section{Ball Milling}

Ball milling/mechanical alloying is a simple and yet effective approach for making thermoelectric nanopowders and has been successfully applied for materials such as $\mathrm{Bi}_{0.5} \mathrm{Sb}_{1.5} \mathrm{Te}$ (Ref. 17), $\mathrm{Si}$ (Ref. 21), and Si-Ge alloy, ${ }^{16}$ etc. Therefore, it can be an attractive technique for producing large-scale quantity of $\mathrm{Mg}_{2} \mathrm{Si}$. In this process, either chucks of polycrystalline $\mathrm{Mg}_{2}(\mathrm{SiSn})$ alloys or elemental powders are loaded into a milling vial, and the vial is inserted in a higher energy milling apparatus. ${ }^{32-34}$ Schilz et al. ${ }^{32}$ reported on the influence of the planetary ball mill setting parameters on the evolution of alloy formation on the thermoelectric semiconductor systems including $\mathrm{Mg}_{2} \mathrm{Si}$ and $\mathrm{Mg}_{2}(\mathrm{SiSn})$ alloys. They observed that in the case of $\mathrm{Mg}_{2} \mathrm{Si}$ and $\mathrm{Mg}_{2}(\mathrm{SiSn})$, the alloying proceeds on the surface of the $\mathrm{Mg}$ bulk particles.

However, $\mathrm{Mg}_{2} \mathrm{Si}$ and its alloys are ductile as opposed to the conventional TE materials that are brittle (e.g., Si-Ge). The "softness" of $\mathrm{Mg}_{2} \mathrm{Si}$ makes it difficult to synthesize via ball milling, ${ }^{35}$ which tends to distort the material by plastic deformation instead of fracturing it, leading to $\mathrm{Mg}$ aggregation. ${ }^{35}$
Xiong et al. ${ }^{33}$ reported the synthesis of nanocrystalline $\mathrm{Mg}_{2} \mathrm{Si}$ by mechanical milling and found that the content of $\mathrm{Mg}_{2} \mathrm{Si}$ phase increases with increasing milling time; however, pure $\mathrm{Mg}_{2} \mathrm{Si}$ phase cannot be obtained by direct ball milling. Moreover, monolithic $\mathrm{Mg}_{2} \mathrm{Si}$ phase could only be obtained when as much as $10 \%$ of excess $\mathrm{Mg}$ was blended in the raw mixtures. The excess $\mathrm{Mg}$ could be agglomerated and oxidized, resulting in impurities in the synthesized powders. Li and Kong ${ }^{36}$ reported that even after $100 \mathrm{~h}$ of milling, phase pure $\mathrm{Mg}_{2} \mathrm{Si}$ could not be synthesized.

Recently, Bux et al. ${ }^{35}$ used an incremental ball milling process to address the problem of $\mathrm{Mg}$ agglomeration. In this process, small amount of $\mathrm{Mg}$ (200-500 mg) was added into a stoichiometric amount of $\mathrm{Si}$ and $\mathrm{Bi}$ and ball milled for intervals of less than $1 \mathrm{~h}$. An additional 200 to $500 \mathrm{mg}$ of increments of $\mathrm{Mg}$ were added and ball milled until the correct stoichiometry was achieved. The reaction could be could be completed within $8 \mathrm{~h}$ depending on the amount of materials. The scanning electron microscope (SEM) shows the powders are made up of mostly large aggregates ranging from $50 \mathrm{~nm}$ to micron sizes (Fig. 4a), while transmission electron microscope (TEM) imaging shows smaller grains size (on the order of $30 \mathrm{~nm}$ ) (Fig. $4 \mathrm{~b}$ ). The synthesized powders were than compacted into pellets via hot pressing for thermoelectric transport measurements. A maximum $Z T$ value of 0.7 was obtained for the samples with optimal Bi concentration $(0.15 \%)$ (Fig. $4 \mathrm{c}$ ). The lower $Z T$ obtained in $\mathrm{Mg}_{2} \mathrm{Si}$ compared to $\mathrm{Mg}_{2}(\mathrm{SiSn})$ reported in Ref. 24 is mainly caused by the higher lattice thermal conductivity $\left(\kappa_{\mathrm{L}}\right.$ are $\sim 2.5$ and $\sim 1.2 \mathrm{~W} / \mathrm{m} \mathrm{K}$ at $800 \mathrm{~K}$ for $\mathrm{Mg}_{2} \mathrm{Si}$, Ref. 35 and $\mathrm{Mg}_{2}(\mathrm{SiSn})$, Ref. 12 , respectively), 
presuming due to the stronger alloy scattering in $\mathrm{Mg}_{2}(\mathrm{SiSn})$ alloys.

\section{Microwave-Assisted Synthesis}

Another highly promising route for the synthesis of nanocrystalline $\mathrm{Mg}_{2} \mathrm{Si}$ is microwave heating, as developed by Gascoin and co-workers. ${ }^{37-39}$ In this route, nanocrystalline $\mathrm{Mg}_{2} \mathrm{Si}$ powders were synthesized at a high yield by employing microwave radiation. The elemental precursors ( $\mathrm{Si}$ and $\mathrm{Mg}$ ) were first milled together under dry conditions to get fine particles. The resulting mixture of powders of $\mathrm{Mg}$ and $\mathrm{Si}$ was cold pressed before being heated by microwave irradiation. The found that that the power and time of the microwave irradiation can be used to control the grain growth of the $\mathrm{Mg}_{2} \mathrm{Si}$ and must be adequately controlled to avoid the decomposition of the phase. Their results show that the method can readily synthesize homogeneous nanocrystalline $\mathrm{Mg}_{2} \mathrm{Si}$ with particle size smaller than $100 \mathrm{~nm}$, with a microwave power of 100 to $200 \mathrm{~W}$ for only a few minutes (on powders ball milled for $2 \mathrm{~h}){ }^{37}$ Maximum $Z T$ values of 0.7 and 0.35 at $770 \mathrm{~K}$ were obtained for $n$ - and $p$-type $\mathrm{Mg}_{2} \mathrm{Si}$-based materials (Fig. 5). ${ }^{39}$

\section{Spark Erosion}

Recently, Berkowitz and co-workers at the University of California at San Diego reported a new process, referred to as "spark erosion," for making nanopowders of thermoelectric materials. ${ }^{40}$ The spark erosion process was originally invented by Berkowitz and Walter to produce micron-sized and amorphous powders of metals. ${ }^{41}$ By tuning the process conditions, Nguyen et al. have demon- strated the application of the spark erosion process in producing large quantity ( $>100 \mathrm{~g}$ scale) of metal and semiconductor nanoparticles. ${ }^{40}$

The basic idea and apparatus of the spark erosion process is shown in Fig. 6, which is a sketch of the spark erosion system. The diameter spark erosion cell, $10 \mathrm{~cm}$ in size, is mounted in a double-walled, vacuum-jacketed glass container that holds the dielectric liquid. Two electrodes of the material of interest are mounted in the cell and connected to the pulsed power source. "Charge" pieces of the same material, $\sim 2 \mathrm{~cm}$ diameter in irregular shapes, fill the perforated Delrin support, making contact with the electrodes. The glass container is vibrated

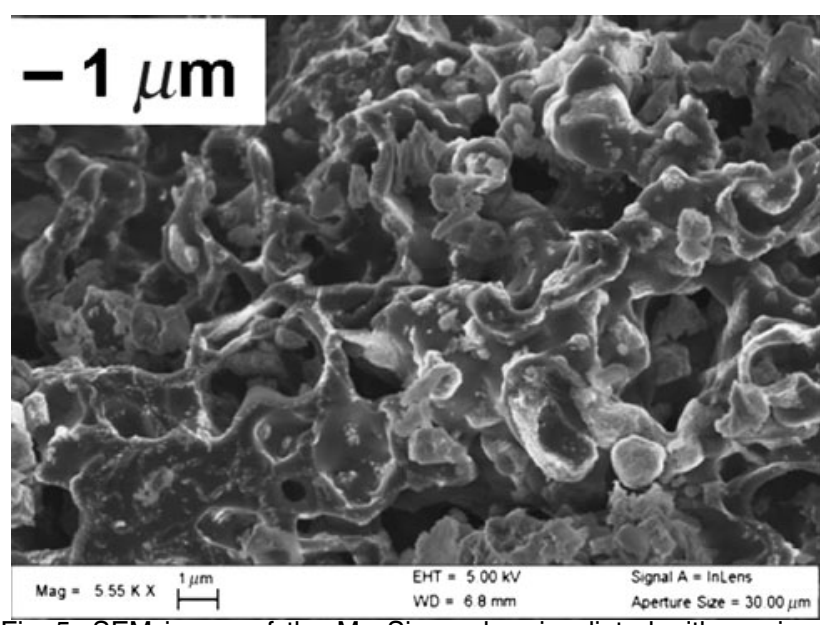

Fig. 5. SEM image of the $\mathrm{Mg}_{2} \mathrm{Si}$ powders irradiated with a microwave power of $200 \mathrm{~W}$ for 10 min (Reprinted with permission from Ref. [37], Copyright 2010, Royal Society of Chemistry).
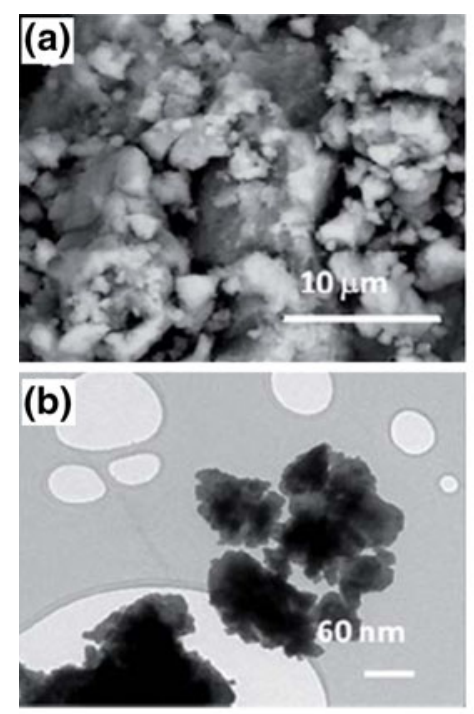

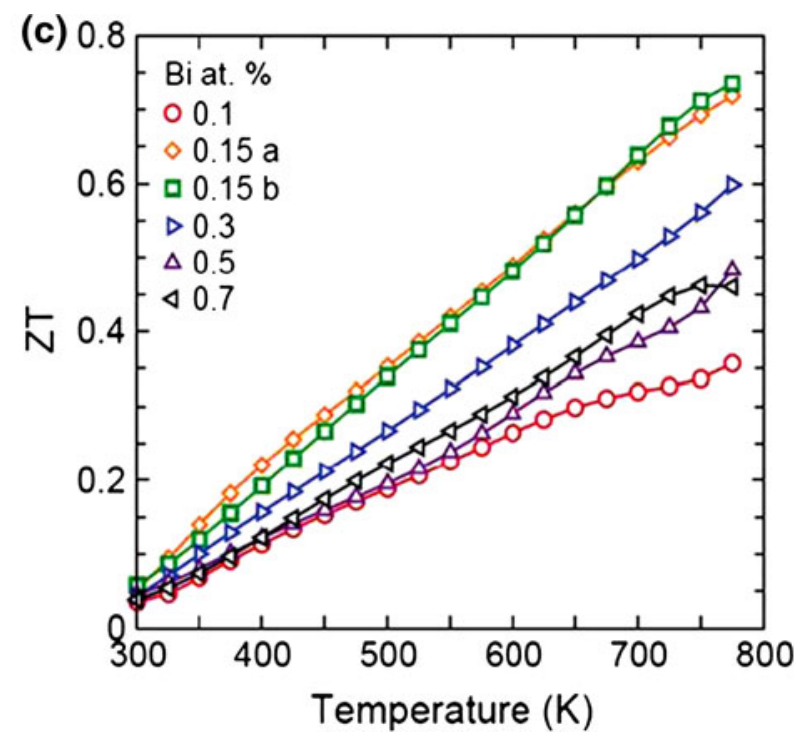

Fig. 4. Mechanochemical synthesis and thermoelectric properties of $\mathrm{Mg}_{2} \mathrm{Si}$. (a) An SEM image shows $\mathrm{Mg}_{2} \mathrm{Si}$ particles ranging in size from nanometers to microns. (b) A TEM image shows that $\mathrm{Mg}_{2} \mathrm{Si}$ aggregates are made up of smaller particles and crystallites. (c) $Z T$ of samples with various $\mathrm{Bi}$ doping concentrations from $300 \mathrm{~K}$ to $800 \mathrm{~K}$. For samples with near-optimum carrier concentrations, $Z T$ values of 0.7 are obtained at 775 K (Reprinted with permission from Ref. [35], Copyright 2011, Royal Society of Chemistry). 
so that contacts among the electrodes and charge pieces are made and broken frequently. Thus, electrical contact between the electrodes is made randomly. The pulsed power source is a charged capacitor. When the gaps among the electrodes and charge pieces are small enough so that the electric

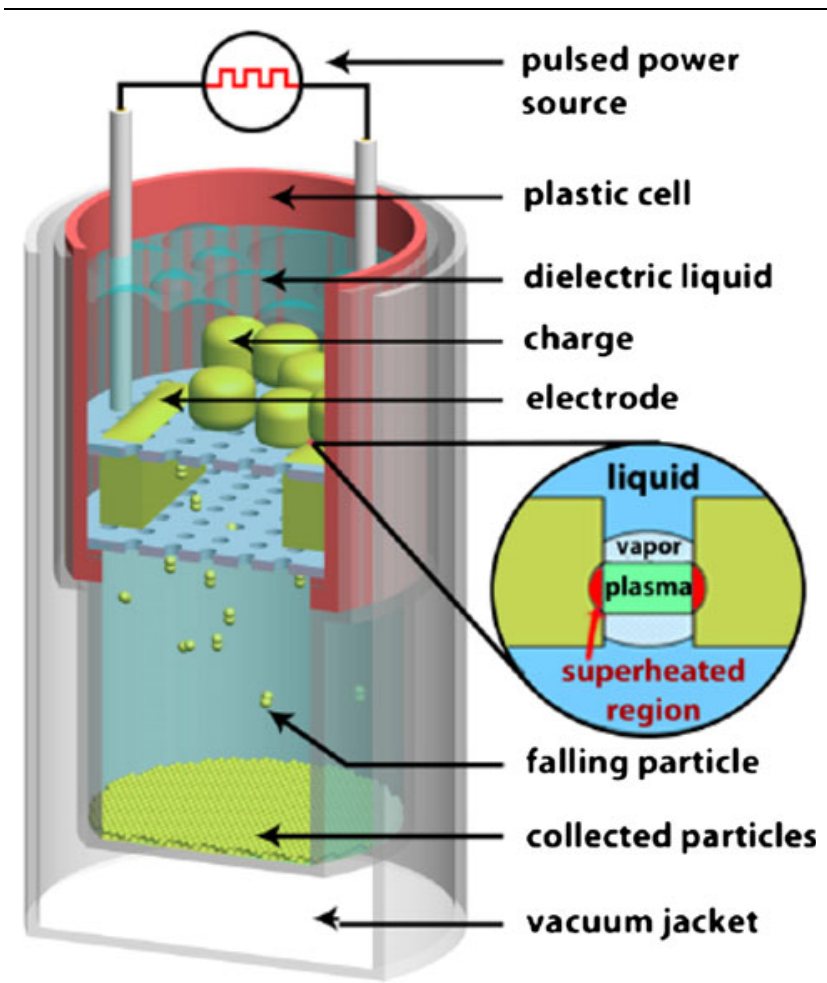

Fig. 6. Sketch of apparatus of the spark erosion process features (Reprinted with permission from Ref. [41], Copyright 2012, IOP Publishing). field across them is larger than the dielectric breakdown field, the capacitor discharges, producing a spark (microplasma) between the pieces involved. This microplasma, consisting of electrons and positive ions, is very hot, at $10,000 \mathrm{~K}$. The kinetic energies of the faster electrons and slower ions are deposited on localized regions where the spark was initiated, superheating them to boiling. When the spark collapses, vaporized alloy and molten droplets are violently ejected from the boiling regions and are propelled though the plasma region into the dielectric liquid, where they are very rapidly quenched. Since the quenching rate is very rapid, particles formed could be very small.

Using this method, Nguyen et al. ${ }^{40}$ reported the synthesis of thermoelectric $\mathrm{Bi}_{0.5} \mathrm{Sb}_{1.5} \mathrm{Te}_{3}$ nanoparticles with a production rate as high as $135 \mathrm{~g} / \mathrm{h}$ using the relatively small laboratory apparatus and low energy consumption. The compacted nanocomposite samples made from these nanoparticles exhibit a well-defined, 20 to 50-nm size nanograin microstructure and show an enhanced figure of merit, $Z T$, of 1.36 at $360 \mathrm{~K}$. This technique is very promising for producing inexpensive and oxidation-free nanoparticles for fabricating high-performance thermoelectric materials.

Because the spark erosion technique does not relied on mechanical ball milling, it is particularly attractive for ductile materials such as $\mathrm{Mg}_{2} \mathrm{Si}$. In this respect, we have carried out the spark erosion process for $\mathrm{Mg}_{2}(\mathrm{SiSn})$. The initial results are very promising. As shown in Fig. 7, the SEM image shows that the spark-eroded powders exhibit nanometer and micron particle sizes, while the TEM image shows a smaller grain size $(\sim 20 \mathrm{~nm})$. Currently, the yield for producing the $\mathrm{Mg}_{2}(\mathrm{SiSn})$ nanopowders is around $5 \mathrm{~g} / \mathrm{h}$. Even though the yield is
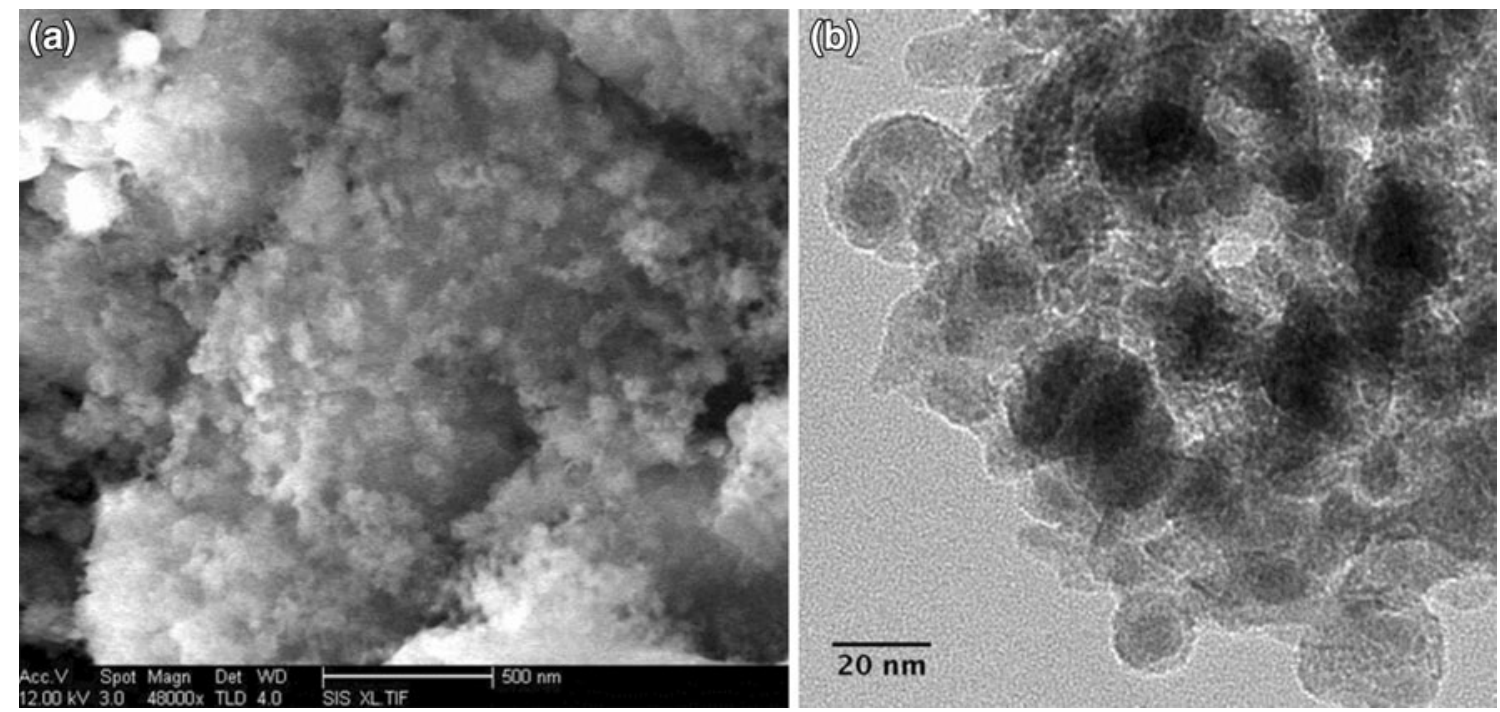

Fig. 7. Nanopowders of $\mathrm{Mg}_{2}(\mathrm{SiSn})$ made from the spark erosion process. SEM imaging (a) shows that the spark-eroded powders exhibit nanometer and micron particle sizes, while the TEM image (b) shows smaller grain size ( 20 nm) (from Moon et al., unpublished, Copyright 2013, University of California, San Diego). 
much lower than that of spark-eroded Bi-Sb-Te (presumably due to the higher melting point of the silicide), it is much faster than that of ball milling. In addition, since the entire process was carried out in dielectric liquids (liquid Ar or N, Ref. 40), oxidation-free nanoparticles of $\mathrm{Mg}_{2}(\mathrm{SiSn})$ can be readily synthesized using this approach. Therefore, this method could be a very promising route for producing a large quantity of high-quality thermoelectric silicide nanopowders.

\section{CONCLUSION}

In conclusion, we summarized some recent development on the fabrication and thermoelectric properties of silicide nanopowders with a focus on $\mathrm{Mg}_{2} \mathrm{Si}$ and its alloys $\left(\mathrm{Mg}_{2}(\mathrm{SiSn})\right)$. Thermoelectric energy conversion could be a transformative technology for improving energy efficiency and providing renewable energy, but the performance-to-cost ratio of thermoelectric devices has to be significantly improved. In this respect, silicide is a very attractive candidate because of Earth abundance, thermal stability, and low toxicity. It is especially attractive for waste heat recovery in the mid-to-high temperature range $(400 \mathrm{~K}$ to $800 \mathrm{~K})$ where it exhibits the peak $Z T$. Nanostructuring has been proven to be a very effective approach to enhance thermoelectric performance in a variety of conventional thermoelectric material systems including $\mathrm{Bi}-\mathrm{Sb}-\mathrm{Te}, \mathrm{CoSb}_{3}$, and Si-Ge; therefore, an increasing amount of effort has been devoted to fabricating silicide nanopowders with the aim of enhancing the $Z T$ values. Different approaches to fabricate $\mathrm{Mg}_{2} \mathrm{Si}$ nanopowders are discussed, including ball milling/mechanical alloying, microwave-assisted synthesis, and spark erosion. It is expected that silicide nanocomposite materials with enhanced $Z T$ are within reach using these and other nanostructuring techniques.

\section{ACKNOWLEDGEMENTS}

The author would like to thank financial support from National Science Foundation (CBET-1140121), as well as help and insights from A. Berkowitz and S. Jin on materials science.

\section{REFERENCES}

1. D. Kraemer, B. Poudel, H.P. Feng, J.C. Caylor, B. Yu, X. Yan, Y. Ma, X.W. Wang, D.Z. Wang, A. Muto, K. McEnaney, M. Chiesa, Z.F. Ren, and G. Chen, Nat. Mater. 10, 532 (2011).

2. J. Yang (Paper presented at the 2005 International Conference on Thermoelectrics, Clemson, SC, 2005).

3. L.E. Bell, Science 321, 1457 (2008).

4. A. Majumdar, Science 303, 777 (2004).

5. X.L. Gou, H. Xiao, and S.W. Yang, Appl. Energy 87, 3131 (2010).

6. D.M. Rowe, CRC Handbook of Thermoelectrics (Boca Raton, FL: CRC Press, 1995).

7. A.J. Minnich, M.S. Dresselhaus, Z.F. Ren, and G. Chen, Energ. Environ. Sci. 2, 466 (2009).

8. T.C. Harman, P.J. Taylor, M.P. Walsh, and B.E. LaForge, Science 297, 2229 (2002).

9. R. Venkatasubramanian, E. Siivola, T. Colpitts, and B. O'Quinn, Nature 413, 597 (2001).
10. A.I. Hochbaum, R.K. Chen, R.D. Delgado, W.J. Liang, E.C. Garnett, M. Najarian, A. Majumdar, and P.D. Yang, Nature 451, 163 (2008).

11. A.I. Boukai, Y. Bunimovich, J. Tahir-Kheli, J.K. Yu, W.A. Goddard, and J.R. Heath, Nature 451, 168 (2008).

12. G.J. Snyder and E.S. Toberer, Nat. Mater. 7, 105 (2008).

13. K.F. Hsu, S. Loo, F. Guo, W. Chen, J.S. Dyck, C. Uher, T. Hogan, E.K. Polychroniadis, and M.G. Kanatzidis, Science 303, 818 (2004).

14. G.S. Nolas, D.T. Morelli, and T.M. Tritt, Annu. Rev. Mater. Sci. 29, 89 (1999).

15. K. Biswas, J.Q. He, I.D. Blum, C.I. Wu, T.P. Hogan, D.N. Seidman, V.P. Dravid, and M.G. Kanatzidis, Nature 489 414 (2012).

16. G. Joshi, H. Lee, Y.C. Lan, X.W. Wang, G.H. Zhu, D.Z. Wang, R.W. Gould, D.C. Cuff, M.Y. Tang, M.S. Dresselhaus, G. Chen, and Z.F. Ren, Nano Lett. 8, 4670 (2008).

17. B. Poudel, Q. Hao, Y. Ma, Y.C. Lan, A. Minnich, B. Yu, X.A. Yan, D.Z. Wang, A. Muto, D. Vashaee, X.Y. Chen, J.M. Liu, M.S. Dresselhaus, G. Chen, and Z.F. Ren, Science 320, 634 (2008).

18. K.C. See, J.P. Feser, C.E. Chen, A. Majumdar, J.J. Urban, and R.A. Segalman, Nano Lett. 10, 4664 (2010).

19. W.J. Xie, X.F. Tang, Y.G. Yan, Q.J. Zhang, and T.M. Tritt, Appl. Phys. Lett. 94, 102111 (2009).

20. G.Q. Zhang, B. Kirk, L.A. Jauregui, H.R. Yang, X.F. Xu, Y.P. Chen, and Y. Wu, Nano Lett. 12, 56 (2012).

21. S.K. Bux, R.G. Blair, P.K. Gogna, H. Lee, G. Chen, M.S. Dresselhaus, R.B. Kaner, and J.P. Fleurial, Adv. Funct. Mater. 19, 2445 (2009).

22. H. Wang, Y.Z. Pei, A.D. LaLonde, and G.J. Snyder, Adv. Mater. 23, 1366 (2011).

23. C.-B. Vining (Paper presented at the IX International Conference on Thermoelectrics [ICT90], Pasadena, CA, 1990).

24. V.K. Zaitsev, M.I. Fedorov, E.A. Gurieva, I.S. Eremin, P.P. Konstantinov, A.Y. Samunin, and M.V. Vedernikov, Phys. Rev. B 74, 045207 (2006).

25. Q.R. Hou, Z.M. Wang, and Y.J. He, Appl. Phys. A-Mater. Sci. Process. 80, 1807 (2005).

26. Q.R. Hou, W. Zhao, Y.B. Chen, D. Liang, X. Feng, H.Y Zhang, and Y.J. He, Phys. Stat. Solidi A-Appl. Mater. Sci. 204, 3429 (2007).

27. H. Nagai, K. Nagai, T. Katsura, S. Katsuyama, K. Majima, and M. Ito, Mater. Trans., JIM 39, 1140 (1998).

28. T. Ohta, C.B. Vining, and C.E. Allevato (Paper presented at the 26th Intersociety Energy Conversion Engineering Conference, Boston, MA, 1991).

29. E. Ratai, M.P. Augustine, and S.M. Kauzlarich, J. Phys. Chem. B. 107, 12573 (2003).

30. R.G. Morris, R.D. Redin, and G.C. Danielson, Phys. Rev. 109, 1909 (1958).

31. Y. Honda, T. Iida, T. Sakamoto, S. S, Y. Taguchi, Y. Mito, T. Nemoto, T. Nakajima, H. Taguchi, K. Nishio, and Y. Takanashi (Paper presented at the Materials Research Society Symposium, 2009).

32. J. Schilz, M. Riffel, K. Pixius, and H.J. Meyer, Powder Technol. 105, 149 (1999).

33. W. Xiong, X.Y. Qin, M.G. Kong, and L. Chen, Trans. Nonferr. Met. Soc. China 16, 987 (2006).

34. L. Wang and X.Y. Qin, Scripta Mater. 49, 243 (2003).

35. S.K. Bux, M.T. Yeung, E.S. Toberer, G.J. Snyder, R.B. Kaner, and J.P. Fleurial, J. Mater. Chem. 21, 12259 (2011).

36. G.H. Li and Q.P. Kong, Scripta Metall. Mater. 32, 1435 (1995).

37. E. Savary, F. Gascoin, and S. Marinel, Dalton Trans. 39, 11074 (2010).

38. E. Savary, F. Gascoin, S. Marinel, and R. Heuguet, Powder Technol. 228, 295 (2012).

39. D. Berthebaud, and F. Gascoin, J. Solid State Chem. (2013).

40. P.K. Nguyen, K.H. Lee, J. Moon, S.I. Kim, K.A. Ahn, L.H Chen, S.M. Lee, R.K. Chen, S. Jin, and A.E. Berkowitz, Nanotechnology 23, 415604 (2012).

41. A.E. Berkowitz and J.L. Walter, Mater. Sci. Eng. 55, 275 (1982). 